\title{
A Microdeletion Proximal of the Critical Deletion Region Is Associated With Mild Wolf-Hirschhorn Syndrome
}

\author{
Femke Hannes, ${ }^{1}$ Peter Hammond, ${ }^{2}$ Oliver Quarrell, ${ }^{3}$ Jean-Pierre Fryns, ${ }^{1}$ Koenraad Devriendt, ${ }^{1}$ \\ and Joris R. Vermeesch ${ }^{1 *}$
}

\author{
${ }^{1}$ Center for Human Genetics, KU Leuven, Belgium \\ ${ }^{2}$ Molecular Medicine Unit, UCL Institute of Child Health, London, UK
}

${ }^{3}$ Sheffield Children's Hospital, Sheffield, UK

Received 24 June 2011; Accepted 1 February 2012

It is generally accepted that the facial phenotype of WolfHirschhorn syndrome is caused by deletions of either WolfHirschhorn critical regions 1 or 2 (WHSCR 1-2). Here, we identify a $432 \mathrm{~kb}$ deletion located $600 \mathrm{~kb}$ proximal to both WHSCR1-2 in a patient with a WHS facial phenotype. Seven genes are underlying this deletion region including FAM193a, ADD1, NOP14, GRK4, MFSD10, SH3BP2, TNIP2. The clinical diagnosis of WHS facial phenotype was confirmed by 3D facial analysis using dense surface modeling. Our results suggest that the WHSCR1-2 flanking sequence contributes directly or indirectly to the severity of WHS. Sequencing the Wolf-Hirschhorn syndrome candidate 1 and 2 genes did not reveal any mutations. Long range position effects of the deletion that could influence gene expression within the WHSCR were excluded in EBV cell lines derived from patient lymphoblasts. We hypothesize that either (1) this locus harbors regulatory sequences which affect gene expression in the WHSCR1-2 in a defined temporal and spatial developmental window or (2) that this locus is additive to deletions of WHSCR1-2 increasing the phenotypic expression. (C) 2012 Wiley Periodicals, Inc.

Key words: Wolf-Hirschhorn syndrome; WHS; microdeletion; 3D facial analysis; Wolf-Hirschhorn critical region

\section{INTRODUCTION}

Wolf-Hirschhorn syndrome (WHS) is characterized by moderate to severe intellectual disability, pre- and postnatal growth retardation, microcephaly, seizures, various organ malformations (e.g., cleft lip and palate), and characteristic facial features. Overall, there is high clinical variability among WHS patients [Estabrooks et al., 1995; Battaglia et al., 1999; Zollino et al., 2000].

Distinctive facial features constitute one of the major diagnostic markers of WHS. The characteristic facial gestalt of WHS patients, also referred to as the Greek warrior helmet facies, is defined by a broad forehead, high nasal bridge, prominent glabella, high arched eyebrows, protruding eyes, hypertelorism, short philtrum, down-

\section{How to Cite this Article:}

Hannes F, Hammond P, Quarrell O, Fryns J-P, Devriendt K, Vermeesch JR. 2012. A microdeletion proximal of the critical deletion region is associated with mild Wolf-Hirschhorn syndrome.

Am J Med Genet Part A 9999:1-9.

turned corners of the mouth, and micrognathia. Moreover, the facial features are more pronounced with severity of the global phenotype [Battaglia et al., 2008]. Age, sex, and medication lead to additional variability of the facial gestalt.

WHS is most often caused by terminal deletions involving chromosome $4 \mathrm{p} 16.3$ and may extend as far as $4 \mathrm{p} 14$ [Shannon et al., 2001]. Interstitial deletions are less frequently reported [Rauch et al., 2001; Van Buggenhout et al., 2004; Basinko et al., 2008; Izumi et al., 2010], but are of particular interest since they facilitate genotype-phenotype correlations and thus the search for causative genes. Early mapping efforts identified two different sized overlapping deletions defining the Wolf-Hirschhorn Syndrome Critical Region 1 (WHSCR1). Further fine mapping resulted in a $165 \mathrm{~kb}$ critical region including two genes, WHSC1 and WHSC2 [Wright et al., 1997]. This region was suggested as responsible for at least two of the core clinical manifestations of WHS, the facial gestalt and developmental delay. Later, two additional patients with partial deletions of the WHSCR1 extending more distally defined a

Additional supporting information may be found in the online version of this article.

The authors report no conflict of interest.

${ }^{\star}$ Correspondence to:

Joris R. Vermeesch, PhD, Center for Human Genetics, Herestraat 49, 3000 Leuven, Belgium. E-mail: joris.vermeesch@med.kuleuven.be Published online 00 Month 2012 in Wiley Online Library (wileyonlinelibrary.com).

DOI 10.1002/ajmg.a.35299 
new critical region WHSCR2 [Zollino et al., 2003; Rodriguez et al., 2005]. Overall, both critical regions 1 and 2 overlap and have one gene, WHSC1, in common. Thus far, all WHS patients carry deletions of the WHSC1 gene [Faravelli et al., 2007; Engbers et al., 2009]. A recent study demonstrated growth retardation and various WHS-like midline defects in whscl haploinsufficient mice. The craniofacial defects similar to those seen in WHS were detected in some $w h s c 1^{+/-}$mice. In addition, double heterozygous mutants, $w h s c 1^{+/-}$and $n k x 2-5^{+/-}$, developed more heart malformations such as atrial and ventricular septal defects (ASD/VSD). Those results indicate that the deletion of WHSC1 alone is not sufficient to account for the entire phenotype, but is modified by additional genetic factors [Nimura et al., 2009].

Here, we report on a patient clinically diagnosed with mild WHS features. Molecular karyotyping revealed a maternally inherited submicroscopic deletion $600 \mathrm{~kb}$ proximal to the currently accepted WHSCR. Objective 3D facial analysis confirmed a mild WHS facial gestalt in the patient and partially in his mother. Our results suggest that this WHSCR flanking sequence contributes directly or indirectly to the severity of WHS.

\section{CLINICAL REPORT}

The male propositus is the second of four siblings. He was born at term after an uneventful pregnancy with birth weight $2.980 \mathrm{~g}$. He presented with feeding difficulties and at the age of 5 years 3 months was referred because of mildly delayed development and attention deficit disorder. He presented with several minor anomalies, such as hypertelorism, cutaneous webbing of the fingers, long fingers, and prominent eyes (Fig. 1). He has a high pitched voice. His height then was $101 \mathrm{~cm}(-2.2 \mathrm{SD})$, weight $15 \mathrm{~kg}(-2.4 \mathrm{SD})$ and head circumference $51 \mathrm{~cm}$ (42nd centile). At the age of 7 years 8 months, he entered special education for children with mild learning disability. His full scale IQ was 61 at age 6 years. He had developed several facial tics, and was taking Ritalin for attention deficit. More recent clinical examination revealed similar features as before. Height was $117.5 \mathrm{~cm}$ ( $3 \mathrm{rd}$ centile), weight $19 \mathrm{~kg}$ ( $3 \mathrm{rd}$ centile $=20 \mathrm{~kg}$ ) and OFC $53 \mathrm{~cm}$ (75th centile). His mother followed normal professional schooling but had attention problems. She has a similar facial phenotype to the propositus. Her height was $155 \mathrm{~cm}$, head OFC $53.3 \mathrm{~cm}$, and both siblings presented without learning difficulties, followed regular schooling and had a normal growth parameter.

\section{MATERIALS AND METHODS}

This study was approved by the "Commissie Medische Ethiek," Faculty of Medicine, Catholic University of Leuven.

\section{Cytogenetic and Molecular Analysis}

Fluorescence in situ hybridization (FISH) with a commercial WHS probe (Cytocell technologies Ltd., Oxford, UK) was performed on metaphase spreads of peripheral blood lymphocytes from the index patient and both parents. DNA was extracted from peripheral blood lymphocytes by the Qiagen DNA extraction kit (Qiagen NV, Venlo, The Netherlands). Array CGH was performed using a homemade

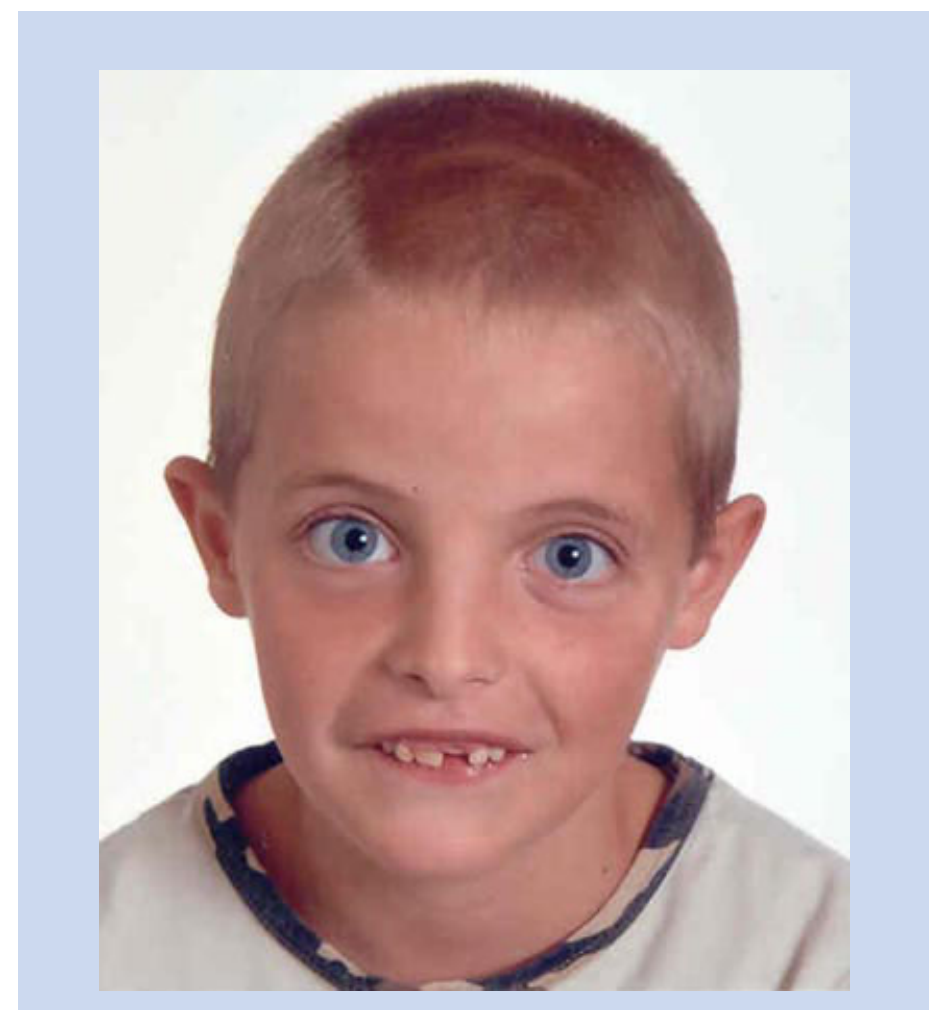

FIG. 1. Picture of the patient.

chromosome 4 tiling BAC array as previously reported [Van Buggenhout et al., 2004]. A custom-made 385k Nimblegen array containing 60 -mer probes spaced every $20 \mathrm{bp}$ was designed to target the region of chromosome $4 \mathrm{p} 16$ between 1.0 and $11.8 \mathrm{Mb}$ (UCSC hg18, http://genome.ucsc.edu/), excluding the highly repetitive regions. Labeling and hybridization followed the instructions of the manufacturer (Roche Nimblegen, Madison, WI). Data extraction, analysis and visualization were done with Nimblescan 2.5 and Signalmap 1.9 (Nimblegen), respectively. To confirm the results of both arrays and to check parental inheritance, FISH analysis was conducted on interphase nuclei of buccal smears of the patient, three siblings and the mother, and metaphase spreads derived from blood lymphocytes of the father. The clone RP11-201O13 (2.679.772-2.747.829 bp), located within the deletion region, was used as a probe for the FISH experiments.

\section{D Facial Analysis}

3D face images of the propositus and family members were collected using a commercial photogrammetric device and each was landmarked by one individual $(\mathrm{PH})$ using 22 reproducible landmarks [Gwilliam et al., 2006]. For the patient and siblings, a comparative image dataset of 200 controls and 100 individuals under 20 years with a genetically confirmed diagnosis of WHS was selected from an existing collection. 3D dense surface models (DSMs) of face shape have delineated common facial features in a range of neurodevelopmental conditions, often, in addition, establishing accurate discriminating characteristics or assisting 
the determination of phenotype-genotype correlations [Hammond et al., 2005]. For this younger group, 20 DSMs were computed using stratified, randomly selected training sets of $90 \%$ of the combined dataset of 300 individuals. In each case, the remaining $10 \%$ was used for blinded discrimination between control and WHS using closest mean classification. Accuracy of classification was estimated as the mean of the areas under the 20 associated receiver operating characteristics (ROC) curves. This corresponds to the probability of correctly classifying a randomly chosen pair of faces, one from each of the control and WHS subgroups. A mean, blinded classification position and $95 \%$ confidence interval was computed for the propositus and siblings using the DSMs from the 20-folded crossvalidation. Finally, a single DSM was computed for the propositus, siblings and 387 controls with a wide age range to enable a facial heat map comparison of the propositus and each sibling with an age and sex matched mean suitably scaled where necessary.

Within the recruited WHS group, only 16 were over 16 years of age. This was too few for an adult-specific analysis of the mother along the lines for the patient and siblings where 100 WHS images were available. In particular, such a small number of WHS images undermines accurate DSM synthesis of dysmorphic facial features. To compensate, we built DSMs using all 108 WHS images of children and adults, as well as 387 controls. Then, within the models, the 40 oldest WHS patients (9.9-32.3 years, mean 16.2 years) and 200 age matched controls (6.2-33.2 years, mean 16.1 years) were used to analyze the mother's face.

To confirm the clinical diagnosis of mild WHS, 22 clinical geneticists had been asked which chromosomal deletion syndrome might best fit the patient's phenotype. Three geneticists suggested WHS; others suggested Aarskog, velocardiofacial, Kabuki, and Smith-Magenis syndromes. Because of these alternative diagnoses we tested the patient against images of children with a FISHconfirmed diagnosis of Smith-Magenis $(n=85)$ and velocardiofacial $(\mathrm{n}=89)$ syndromes. No images were available for testing for facial features of Aarskog and Kabuki syndromes.

\section{Cell Culture, RNA, and cDNA Preparations}

Epstein Barr virus (EBV) transformed lymphoblasts derived from the patient and 10 control individuals were grown in DMEM/F-12 media supplemented with $10 \%$ fetal calf serum. Total RNA was prepared in parallel from logarithmic growth-phase cells with RNeasy Mini kit (QIAGEN Benelux B.V., Venlo, Netherlands) in accordance with the manufacturer's instructions. DNAse treatment (Roche Diagnostics Belgium, Vilvoorde, Belgium) was performed and subsequently converted to cDNA with the use of Superscript III (Life Technologies Europe B.V., Gent, Belgium) primed with a combination of both oligo $\mathrm{d}(\mathrm{T})$ (Invitrogen) and random primers (Invitrogen).

\section{Real-Time Quantitative PCR (RT qPCR) and Data Analysis}

Primers for RT qPCR were designed to span an intron boundary when possible using the Universal ProbeLibrary Assay Design Center (Roche Diagnostics Belgium, Vilvoorde, Belgium). Primers containing SNPs or repetitive sequences were excluded using the
dbSNP and blat tool from the UCSC browser (http://genome.ucsc.edu/). The runs were performed in the Ligthcycler 480 instrument I using the LightCycler ${ }^{\circledR} 480$ SYBR Green I Master mix (Roche Applied science). In total, 22 genes located from the telomere of chromosome $4 \mathrm{p}$ to approximately $4.5 \mathrm{Mb}$ were selected. Three genes, GUSB, CLK2, and ACTB were used for normalization of the expression data. Final working volume of $20 \mu \mathrm{l}$ contained $0.5 \mu \mathrm{M}$ of primers, $10 \mu \mathrm{l}$ SybrGreen I Master mix, and $5 \mu \mathrm{l}$ of template cDNA (in total 33.3 or $66.7 \mathrm{ng}$ ) and each sample was conducted in replicate. The complete experiment was repeated two times. The raw data were extracted from the Lightcylcer 480 software and subsequently analyzed and stored via qBase (qBase-user manual v1.3.5).

\section{Breakpoint Spanning PCR and Sequencing}

Breakpoint spanning PCR was performed with both primers (Eurogentec, Liege, Belgium) designed in normal copy number regions flanking the breakpoints. The amplification was conducted in a total volume of $50 \mu \mathrm{l}$ including $200 \mu \mathrm{M}$ dNTPs, $250 \mathrm{nM}$ of both primers, $1.5 \mathrm{mM} \mathrm{MgCl} 2,2.5 \mathrm{U}$ platinum Taq polymerase (Invitrogen), and $100 \mathrm{ng}$ template DNA. Following amplification program was used; one cycle of $5 \mathrm{~min}$ on $95^{\circ} \mathrm{C} ; 30$ cycles of $95^{\circ} \mathrm{C}-30 \mathrm{sec}, 5 \mathrm{X}^{\circ} \mathrm{C}-30 \mathrm{sec}, 72^{\circ} \mathrm{C}-2 \mathrm{~min}$; and one cycle of $72^{\circ} \mathrm{C}-10 \mathrm{~min}$. The product was subsequently Sanger sequenced using the BigDye terminator system. The resulting labeled fragments were size separated using an ABI 3130xl sequencer.

\section{Sequencing of WHSC1 and 2 Gene}

DNA extracted from peripheral blood lymphocytes was used to sequence both WHS candidate genes. Primer design within the intronic region was done via Primer3 (http://ihg2.helmholtzmuenchen.de/ihg/ExonPrimer.html). PCR was optimized and the products were subsequently sequenced on an ABI 3130 automated capillary DNA sequencer using the BigDye Terminator v. 3.1 Cycle Sequencing Kit (Applied Biosystems, Lennik, Belgium).

\section{RESULTS}

\section{Molecular Characterization of the Deletion}

Following clinical examination, microdeletion on chromosome $4 \mathrm{p}$ was suggested. FISH analysis using a commercial probe covering both WHSCRs on metaphase spreads of the patient was normal. Subsequent molecular karyotyping with a homemade chromosome 4 BAC tiling array detected a submicroscopic interstitial deletion $600 \mathrm{~kb}$ proximal to the WHSCR. The boundaries of the deletion were defined by two normal flanking clones, RP11-448F22 (2.384.345 bp) and RP11-355N4 (3.094.606 bp), and two deleted clones, RP11-677N20 (2.646.413 bp) and RP11-705L9 (2.996.839 bp). Array CGH using a targeted 385k targeted Nimblegen array redefined the deletion size to $432 \mathrm{~kb}$ (Fig. 2A). Breakpoint-spanning PCR combined with sequence analysis revealed the exact location of both distal and proximal breakpoints at 2.605.128 and 3.036.901 bp, respectively (Human genome build 18) (Fig. 2C). Both distal and proximal breakpoints are located within repeat sequences including a long interspersed nuclear element (LINE) at 


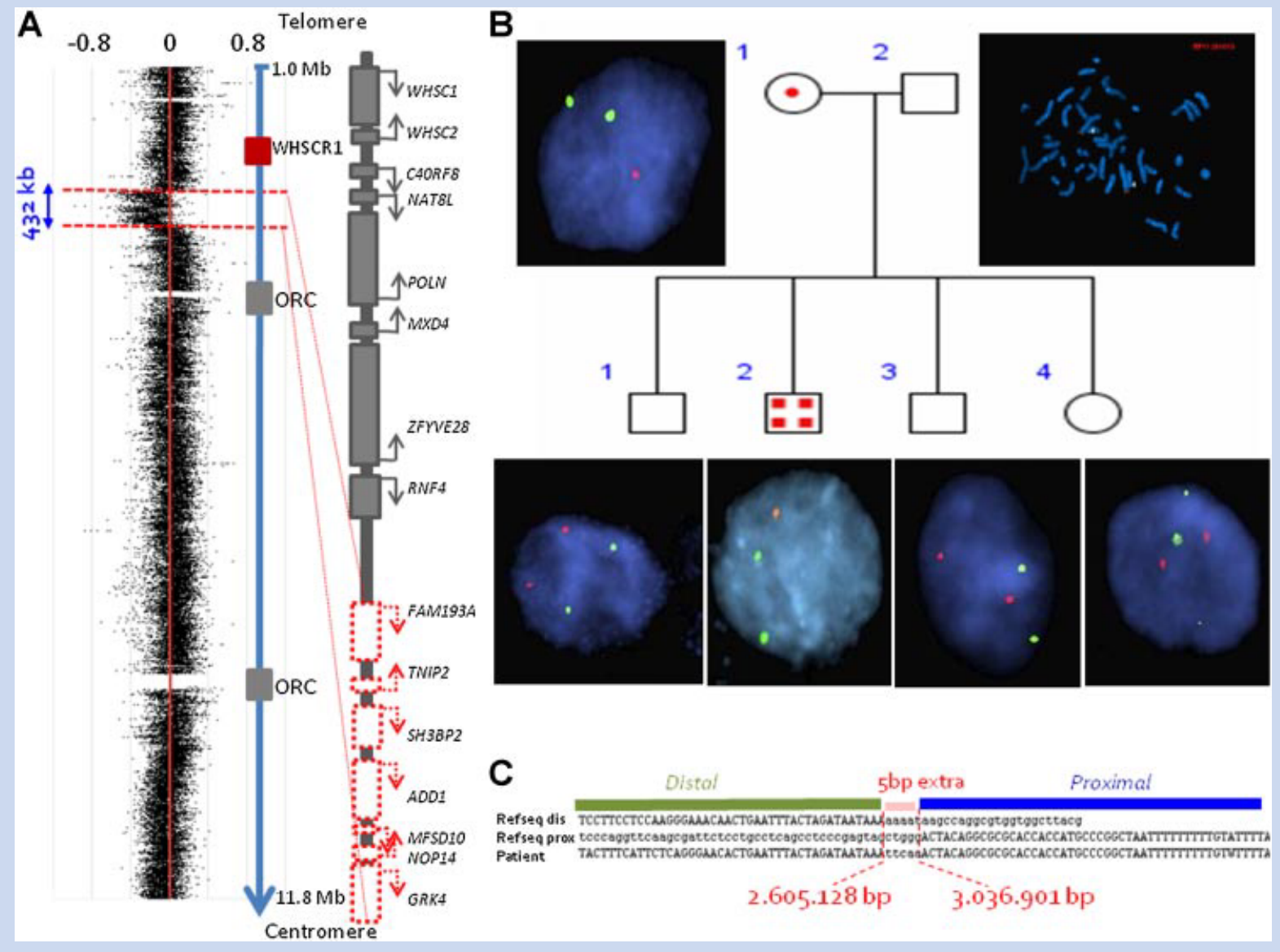

FIG. 2. Overview of the cytogenetic and molecular data. A: The results of the high resolution oligonucleotide microarray of Nimblegen targeting a region of 1.0-11.8 Mb. Each dot represents a combination of 10 probes targeting a region of approximately 200 bp. The red box depicts the location of the WHSCR and the two other gray boxes indicate the locations of both olfactory receptor gene clusters [ORC]. The dotted boxes represent the genes within the deletion region. B: The red color represents a clone RP11-201013 and the green dot, a subtelomere 4q. C: Sequence analysis of the breakpoint junction.

the distal site and a short interspersed nuclear element (SINE) at the proximal site. Interspersed between both breakpoints are 5 nucleotides of unknown origin, suggesting that the deletion was repaired by non-homologous-end-joining (NHEJ). Within this deletion region, 7 refseq genes are located including FAM193A, TNIP2, SH3BP2, ADD1, NOP14, GRK4, and MFSD10. This deletion has not been reported in patients nor in normal individuals so far (Pubmed; http://www.ncbi.nlm.nih.gov/pubmed, own in-house database and database of genomic variants, http:// projects.tcag.ca/variation/). Analysis of the database of genomic variants reveals three copy number variations in 2,502 normal individuals partially covering the region including two genes TNIP2 and SH3BP2 [Stec et al., 1998; Shaikh et al., 2009]. No clinical details could be obtained regarding WHS-like facial morphology or other manifestations as seen in our patient. Therefore, we cannot exclude them from the set of candidate genes.

FISH using clone RP11-201O13, located within the deletion region, was hybridized on interphase nuclei of buccal smear from the mother and the four siblings (Fig. 2B) as well as on metaphase spreads of both father and mother. FISH analysis confirmed a deletion in the patient. As expected, a deletion was detected in the nuclei of the mother who presented with similar WHS facial features (Fig. 2B). The phenotypically normal siblings and father were diploid for this locus. Taken together, these results indicate a maternal inheritance of the deletion.

\section{Confirmation of WHS Facial Phenotype}

Because this deletion is outside the critical region and the clinical diagnosis is rather subjective, we aimed to confirm the diagnosis using an additional, objective method. Hereto, 3D facial capturing was applied to all family members but the father. The results for the propositus and siblings are shown in Figure 3A. The 20-folded facial analysis of the younger dataset produced an estimated classification accuracy of 0.999 on a scale of [0.1]. The background scatter is included solely to indicate typical classification positions and was not the referrant population. It is computed from a single DSM for all 300 younger subjects. The propositus' face is classified unseen as more WHS-like than control-like. In contrast, his three siblings are classified as more-control-like than WHS-like. The single DSM 


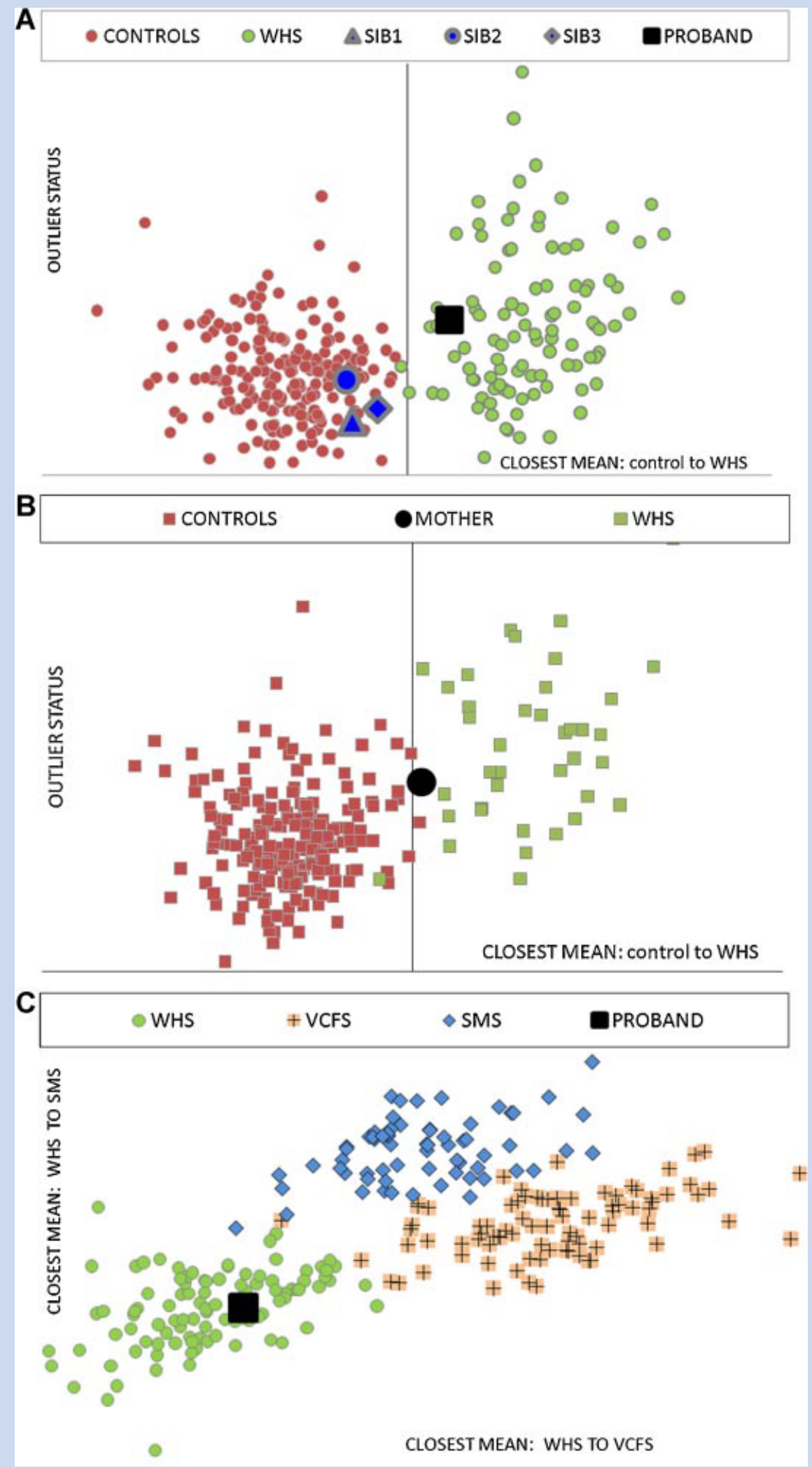

FIG. 3. Overview of the facial analysis. Classifications showing (A) face of patient and sibs respectively as more WHS-like and more control-like; [B] mother's face as borderline control-WHS but slightly more WHS-like; and (C) patient's face as more WHS-like than Smith-Magenis-like [SMS] or velocardiofacial-like (VCFS). 
based on controls $(n=200)$ and individuals with one of three syndromes (WHS-100; SMS-85; VCFS-89) produced a three-way 2-D scatter (Fig. 3B) that classifies the propositus' face unseen as more like WHS than the other two. A four-way controlWHS-SMS-VCFS closest mean comparison resulted in a 3D scatter animated in the Supplementary eVideo S1 (see online in Supporting Information). This classifies the patient unseen within the WHS group some distance from the SMS and VCFS clusters, and, the three siblings within the control cluster. Supplementary eFigure S1 (see online in Supporting Information) shows heat maps reflecting differences parallel to three orthogonal axes of the mean WHS face, the propositus and three siblings compared to age/sex/ ethnicity matched control means computed from 50 contiguously aged controls. The first column comparing WHS mean to a sizeadjusted control mean highlights the characteristic features. The third, fourth and fifth columns do not reveal any WHS-like features in the three siblings and corroborate their earlier quantitative closest mean classifications as control-like. The second column highlights the propositus' mild WHS-like features: relatively wide palpebral fissures and mild hypertelorism (red-green on exocanthi in A); upsweep to the supra-orbital region (blue on supraorbit in B), short and curled philtrum (blue on lip center in B), prominent glabella (blue on forehead in C) and, broad nasal bridge (blue on nasal bridge in C).

Within DSMs based on 108 WHS subjects and 387 controls, the face of the patient's mother was compared unseen with a subset of 40 WHS patients and 200 controls. A closest mean classification based on 33 modes of the underlying DSM (corresponding to 99\% variance coverage) classified her face on the periphery of the WHS and control clusters but slightly closer to the control mean. On inspection, her face synthesis did not accurately reflect the shape of her nose. In contrast, a DSM for just a nasal patch and the same population did and classified her nose shape as WHS with DSM modes corresponding to $99 \%$ variance coverage (Supplementary eFig. S2-See online in Supporting Information). Extending the number of modes derived from the face DSM by 3 to $99.1 \%$ variance coverage improved the accuracy of her face synthesis and moved her classification position marginally, still peripheral to both groups but now more WHS-like than control-like (Fig. 3C). These results suggest that the mother has some WHS-like facial dysmorphism, especially around the nasal region. However, their sensitivity to small changes in variance coverage emphasizes that the small number of available adult WHS images cannot support the same robust analysis completed for the patient. A more complete analysis will have to await additional adult WHS recruitment.

Taken together, the combined finding of this particular microdeletion and the WHS facial phenotype is surprising. These results strongly suggest a causal relationship between the mild WHS facial features in the propositus and the chromosome $4 \mathrm{p}$ deletion.

\section{Expression and Mutation Analysis of Both Genes Within the WHSCR1}

All previous evidence indicates that haploinsufficiency of WHSC1 and/or WHSC2 are essential to cause mild WHS, so the finding of a more proximal deletion is surprising. One explanation could be the presence of a co-segregating mutation with the deletion in this family. To evaluate the possibility of a co-segrating mutation in the WHSC1 and/or 2 gene, we sequenced the complete coding sequence in the patient and a control individual. No mutations were detected. Moreover, the tiling resolution array excluded small intragenic WHSCR 1 and 2 deletions.

A second possibility could be a long range position-effect that alters gene-expression within the WHSCR 1 and surrounding genes. Real-Time quantitative PCR was performed on cDNA extracted from EBV cultured lymphoblasts obtained from the patient and ten control individuals. For five out of seven hemizygous genes, the expression levels were stable in controls and expression was approximately half of that in controls (Fig. 4). The expression levels of 13 genes located distal to the deletion and four genes located proximal to the deletion showed normal expression levels and were similar to those seen in controls. For one gene, TACC3, a minimal decrease in the expression value was noticed (0.76) (Fig. 4). TACC3 expression in normal individuals remained within the threshold values $(0.8 \pm 0.14)$ and thus the value in the index patient falls within the normal range. Hence, no long range position effect originating from the deletion region on either both WHSCR1-2 nor any other genes flanking the critical regions could be observed in EBV cell lines. Conversely, an effect of the WHSCR on gene expression in the deletion region was excluded by investigating a patient with a terminal $4 p$ deletion encompassing the WHSCR but not the newly identified deletion.

\section{DISCUSSION}

Thus far, deletions in the WHS critical region are considered the molecular hallmark of WHS. Here, we identify a submicroscopic interstitial deletion $600 \mathrm{~kb}$ proximal to the WHSCR in a patient and his mother who both have mild WHS features. Since the clinical assessment of the facial gestalt is subjective, we applied dense surface modeling analysis which confirmed the WHS-like facial features. Several mechanisms can be envisioned on how this deletion might contribute to the WHS phenotype.

First, the deletion region might harbor control elements that regulate the expression of genes in WHSCRs. Disruption of distant cis-regulatory control elements of genes like PAX6, FOXL2, and SOX9, lead to aniridia [Lauderdale et al., 2000], blepharophimosis syndrome (BPES) [Beysen et al., 2005], and Pierre Robin sequence (PRS) [Benko et al., 2009], respectively. This deregulation is described on both sides of the gene and caused by disruptions $10 \mathrm{~kb}$ to $1.5 \mathrm{Mb}$ away. We investigated similar long-range effects by expression analysis in EBV cell lines. This did not reveal any aberrant expression of genes within WHSCR1 and 2 and flanking genes approximately $600 \mathrm{~kb}$ away from the deletion. Another possibility is that loci within the WHSCR1 and WHSCR2 exert a long range effect on one or more genes in the newly identified deletion region and that in fact reduced expression of these genes explains the WHS-like phenotype. This would explain why mutations in WHSC1 or WHSC2 have never been observed in WHS-like patients [Stec et al., 1998; Maas et al., 2008]. However, expression analysis in an EBV cell line with a terminal deletion including WHSCR1 and 2 did not reveal reduced expression of the genes in this novel deletion region. Since WHS is a developmental disorder, 


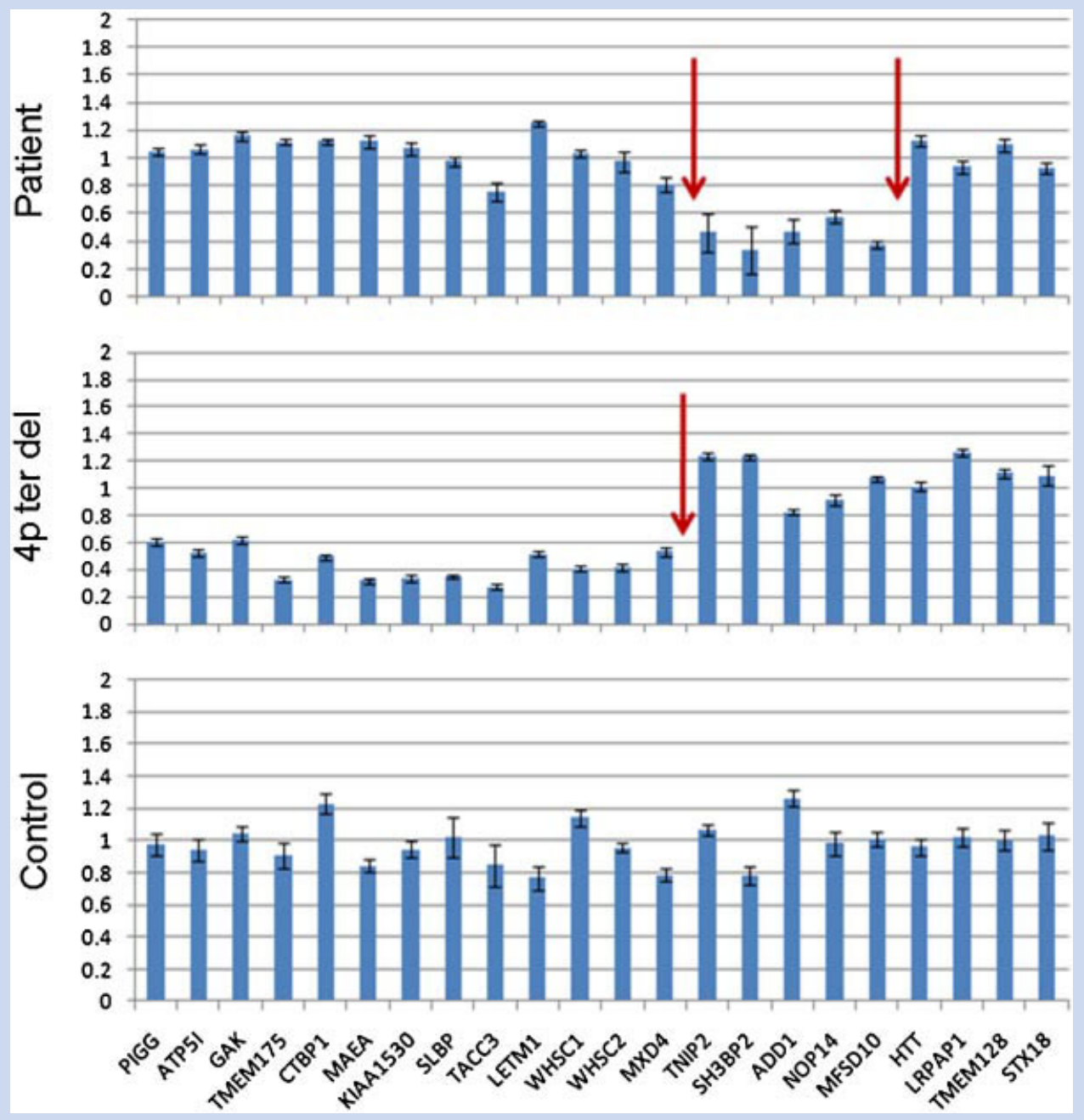

FIG. 4. Overview of the expression analysis for 22 genes, organized starting from the telomere (left) toward the centromere (right), within and surrounding the deletion region in (A) the patient described here, $(B)$ a second WHS patient carrier of a terminal deletion including both WHSCR1-2, and $(C)$ one control individual. The arrows depict the deletion boundaries.

gene expression in lymphoblasts is not necessarily representative of the expression of those genes in the different tissues shaping the face during embryonal development. Therefore, we cannot exclude a cell type specific position-effect. To study this hypothesis further, animal models will be essential.

Another possibility is that the deletion could be fortuitous and another genetic cause is co-segregating with the phenotype. Since the most likely candidate genes to cause the WHS facial gestalt are the WHSC1 and 2 genes, we sequenced both of them. This analysis did not reveal any mutation which is in line with previous sequencing efforts in WHS-like patients [Stec et al., 1998; Maas et al., 2008].

Two genes, WHSC1 and LETM1, have been confirmed as being involved in the pathogenesis of WHS. WHSC1 is thought to cause developmental delay and the specific WHS facial gestalt, because, until recently, all patients were carriers of a partial or complete deletion of this particular gene [Rauch et al., 2001]. However, a few reports have described patients who retain WHSC1, but who are suggestive for the facial phenotype [Faravelli et al., 2007; Engbers et al., 2009]. Both deletions were distally located from the WHSCR1. In a recent publication, $3 \mathrm{D}$ facial capturing was performed on patients suggestive for WHS with deletions either located distally to the WHSCR1 and/or overlapping the WHSCR1 [Hammond et al., 2011]. Using dense surface modeling and pattern recognition techniques, isolated WHS facial features were demonstrated in WHS-like patients whereas the full complement of the WHS facial characteristics are noted in typical WHS patients. Although similar features were present in our patient, small differences are noted such as the absence of micrognatia, mild hypertelorism, mild proptosis, and a prominent nasal bridge. Taken together, this demonstrates that the hemizygosity of the WHSC1 gene alone is not sufficient and thus the interplay with other loci is necessary to express the complete distinct facial phenotype seen in typical WHS patients.

There is already evidence for additive effects. Firstly, genotypephenotype correlations have shown that manifestations such as microcephaly, cleft lip, and palate and intellectual disability are 
probably the result of haploinsufficiency of more than one gene in the region [Van Buggenhout et al., 2004]. Secondly, several genes located on chromosome $4 \mathrm{p} 16$ are known to interact. For example, TACC 3 and $C T B P 1$ both interact with the transcriptional regulator FOG-1 [Katz et al., 2002; Garriga-Canut et al., 2006] and SLBP and the NELF complex (a multi-subunit complex that includes WHSC2) are both players in the same pathway involving the translation of replication-dependent histones [Narita et al., 2007]. Taken together, those observations suggest that WHS is in fact a true contiguous gene syndrome and that haploinsufficiency of multiple genes is necessary for the presentation of the full blown WHS phenotype.

Deletion of either this region or the WHSCR1 leads to mild phenotypic effects, whereas deletion of both loci produces a more pronounced facial phenotype. The DSM-based analysis identified mild WHS facial features in the patient and partial WHS features in the mother.

Another possibility is that hemizygosity of the genes in the region are directly involved in the representation of the mild WHS facial gestalt. The deletion region itself contains seven refseq genes. Thus far, none of those genes has been associated with the etiology of WHS. One gene, FAM193a, is a hypothetical protein with unknown function. $A D D 1$ encodes for a cytoskeleton protein, and NOP14 is involved in processing of the pre-18S-rRNA fraction. GRK4 encodes a $G$ protein coupled receptor kinase, which is presumably linked to hypertension. MFSD10 is a major facilitator superfamily of transporter proteins and likely plays a role in the efflux of organic anions. Gain of function mutations in $\mathrm{SH} 3 \mathrm{BP} 2$ are well known to cause cherubism and finally, TNIP2 is an inhibitor of the NF-KappaB activation. The mouse phenotype derived from a null allele for Tnip2 results in an impaired IL-1 response and macrophage physiology.

Genotype-phenotype correlation aims to improve gene identification involved in the pathogenesis of the genetic syndrome. However, due to the high phenotypic variability between the different WHS patients, genotype-phenotype correlations are not always informative. Unraveling the factors that contribute to the phenotypic variability is important for understanding the disease process and for patient counseling. One approach to pinpoint genes involved in biological variation is to study expression profiles of the loci of interest and their surroundings. In conclusion, we report that a microdeletion $600 \mathrm{~kb}$ proximally of the WHSCR leads to a borderline WHS phenotype and propose that this locus predisposes to WHS.

\section{REFERENCES}

Basinko A, Douet-Guilbert N, Parent P, Blondin G, Mingam M, Monot F, Morel F, Le Bris MJ, De Braekeleer M. 2008. Familial interstitial deletion of the short arm of chromosome 4 (p15.33-p16.3) characterized by molecular cytogenetic analysis. Am J Med Genet Part A 146A:899903.

Battaglia A, Carey JC, Cederholm P, Viskochil DH, Brothman AR, Galasso C. 1999. Natural history of Wolf-Hirschhorn syndrome: Experience with 15 cases. Pediatrics 103:830-836.

Battaglia A, Filippi T, Carey JC. 2008. Update on the clinical features and natural history of Wolf-Hirschhorn (4p-) syndrome: Experience with 87 patients and recommendations for routine health supervision. Am J Med Genet Part C 148C:246-251.

Benko S, Fantes JA, Amiel J, Kleinjan DJ, Thomas S, Ramsay J, Jamshidi N, Essafi A, Heaney S, Gordon CT, McBride D, Golzio C, Fisher M, Perry P, Abadie V, Ayuso C, Holder-Espinasse M, Kilpatrick N, Lees MM, Picard A, Temple IK, Thomas P, Vazquez MP, Vekemans M, Roest Crollius H, Hastie ND, Munnich A, Etchevers HC, Pelet A, Farlie PG, Fitzpatrick DR, Lyonnet S. 2009. Highly conserved non-coding elements on either side of SOX9 associated with Pierre Robin sequence. Nat Genet 41: 359-364.

Beysen D, Raes J, Leroy BP, Lucassen A, Yates JR, Clayton-Smith J, Ilyina H, Brooks SS, Christin-Maitre S, Fellous M, Fryns JP, Kim JR, Lapunzina P, Lemyre E, Meire F, Messiaen LM, Oley C, Splitt M, Thomson J, Van de Peer Y, Veitia RA, De Paepe A, De Baere E. 2005. Deletions involving long-range conserved nongenic sequences upstream and downstream of FOXL2 as a novel disease-causing mechanism in blepharophimosis syndrome. Am J Hum Genet 77:205-218.

Engbers H, van der Smagt JJ, van't Slot R, Vermeesch JR, Hochstenbach R, Poot M. 2009. Wolf-Hirschhorn syndrome facial dysmorphic features in a patient with a terminal 4 p16.3 deletion telomeric to the WHSCR and WHSCR 2 regions. Eur J Hum Genet 17:129-132.

Estabrooks LL, Rao KW, Driscoll DA, Crandall BF, Dean JC, Ikonen E, Korf B, Aylsworth AS. 1995. Preliminary phenotypic map of chromosome 4p16 based on 4p deletions. Am J Med Genet 57:581-586.

Faravelli F, Murdolo M, Marangi G, Bricarelli FD, Di Rocco M, Zollino M. 2007. Mother to son amplification of a small subtelomeric deletion: A new mechanism of familial recurrence in microdeletion syndromes. Am J Med Genet Part A 143A:1169-1173.

Garriga-Canut M, Schoenike B, Qazi R, Bergendahl K, Daley TJ, Pfender RM, Morrison JF, Ockuly J, Stafstrom C, Sutula T, Roopra A. 2006. 2-Deoxy-D-glucose reduces epilepsy progression by NRSF-CtBPdependent metabolic regulation of chromatin structure. Nat Neurosci 9:1382-1387.

Gwilliam JR, Cunningham SJ, Hutton T. 2006. Reproducibility of soft tissue landmarks on three-dimensional facial scans. Eur J Orthod 28:408-415.

Hammond P, Hutton TJ, Allanson JE, Buxton B, Campbell LE, ClaytonSmith J, Donnai D, Karmiloff-Smith A, Metcalfe K, Murphy KC, Patton M, Pober B, Prescott K, Scambler P, Shaw A, Smith AC, Stevens AF, Temple IK, Hennekam R, Tassabehji M. 2005. Discriminating power of localized three-dimensional facial morphology. Am J Hum Genet 77:999-1010.

Hammond P, Hannes F, Suttie M, Devriendt K, Vermeesch JR, Faravelli F, Forzano F, Parekh S, Williams S, McMullan D, South ST, Carey JC, Quarrell O. 2012. Fine-grained facial phenotype-genotype analysis in Wolf-Hirschhorn syndrome. Eur J Hum Genet 20:33-40.

Izumi K, Okuno H, Maeyama K, Sato S, Yamamoto T, Torii C, Kosaki R, Takahashi T, Kosaki K. 2010. Interstitial microdeletion of 4p16.3: Contribution of WHSC1 haploinsufficiency to the pathogenesis of developmental delay in Wolf-Hirschhorn syndrome. Am J Med Genet Part A 152A:1028-1032.

Katz SG, Cantor AB, Orkin SH. 2002. Interaction between FOG-1 and the corepressor C-terminal binding protein is dispensable for normal erythropoiesis in vivo. Mol Cell Biol 22:3121-3128.

Lauderdale JD, Wilensky JS, Oliver ER, Walton DS, Glaser T. 2000. $3^{\prime}$ deletions cause aniridia by preventing PAX6 gene expression. Proc Natl Acad Sci USA 97:13755-13759.

Maas NM, Van Buggenhout G, Hannes F, Thienpont B, Sanlaville D, Kok K, Midro A, Andrieux J, Anderlid BM, Schoumans J, Hordijk R, Devriendt K, Fryns JP, Vermeesch JR. 2008. Genotype-phenotype correlation in 21 patients with Wolf-Hirschhorn syndrome using high resolution array comparative genome hybridisation (CGH). J Med Genet 45:71-80. 
Narita T, Yung TM, Yamamoto J, Tsuboi Y, Tanabe H, Tanaka K, Yamaguchi Y, Handa H. 2007. NELF interacts with CBC and participates in 3' end processing of replication-dependent histone mRNAs. Mol Cell 26:349-365.

Nimura K, Ura K, Shiratori H, Ikawa M, Okabe M, Schwartz RJ, Kaneda Y. 2009. A histone $\mathrm{H} 3$ lysine 36 trimethyltransferase links $\mathrm{Nkx} 2-5$ to Wolf-Hirschhorn syndrome. Nature 460:287-291.

Rauch A, Schellmoser S, Kraus C, Dorr HG, Trautmann U, Altherr MR, Pfeiffer RA, Reis A. 2001. First known microdeletion within the Wolf-Hirschhorn syndrome critical region refines genotype-phenotype correlation. Am J Med Genet 99:338-342.

Rodriguez L, Zollino M, Climent S, Mansilla E, Lopez-Grondona F, Martinez-Fernandez ML, Murdolo M, Martinez-Frias ML. 2005. The new Wolf-Hirschhorn syndrome critical region (WHSCR-2): A description of a second case. Am J Med Genet Part A 136A:175-178.

Shaikh TH, Gai X, Perin JC, Glessner JT, Xie H, Murphy K, O’Hara R, Casalunovo T, Conlin LK, D'Arcy M, Frackelton EC, Geiger EA, Haldeman-Englert C, Imielinski M, Kim CE, Medne L, Annaiah K, Bradfield JP, Dabaghyan E, Eckert A, Onyiah CC, Ostapenko S, Otieno FG, Santa E, Shaner JL, Skraban R, Smith RM, Elia J, Goldmuntz E, Spinner NB, Zackai EH, Chiavacci RM, Grundmeier R, Rappaport EF, Grant SF, White PS, Hakonarson H. 2009. High-resolution mapping and analysis of copy number variations in the human genome: A data resource for clinical and research applications. Genome Res 19:1682-1690.

Shannon NL, Maltby EL, Rigby AS, Quarrell OW.2001. An epidemiological study of Wolf-Hirschhorn syndrome: Life expectancy and cause of mortality. J Med Genet 38:674-679.
Stec I, Wright TJ, van Ommen GJ, de Boer PA, van Haeringen A, Moorman AF, Altherr MR, den Dunnen JT. 1998. WHSC1, a $90 \mathrm{~kb}$ SET domaincontaining gene, expressed in early development and homologous to a Drosophila dysmorphy gene maps in the Wolf-Hirschhorn syndrome critical region and is fused to IgH in $\mathrm{t}(4 ; 14)$ multiple myeloma. Hum Mol Genet 7:1071-1082.

Van Buggenhout G, Melotte C, Dutta B, Froyen G, Van Hummelen P, Marynen P, Matthijs G, de Ravel T, Devriendt K, Fryns JP, Vermeesch JR. 2004. Mild Wolf-Hirschhorn syndrome: Micro-array CGH analysis of atypical 4 p 16.3 deletions enables refinement of the genotype-phenotype map. J Med Genet 41:691-698.

Wright TJ, Ricke DO, Denison K, Abmayr S, Cotter PD, Hirschhorn K, Keinanen M, McDonald-McGinn D, Somer M, Spinner N, Yang-Feng T, Zackai E, Altherr MR. 1997. A transcript map of the newly defined $165 \mathrm{~kb}$ Wolf-Hirschhorn syndrome critical region. Hum Mol Genet 6:317324.

Zollino M, Di Stefano C, Zampino G, Mastroiacovo P, Wright TJ, Sorge G, Selicorni A, Tenconi R, Zappala A, Battaglia A, Di Rocco M, Palka G, Pallotta R, Altherr MR, Neri G. 2000. Genotype-phenotype correlations and clinical diagnostic criteria in Wolf-Hirschhorn syndrome. Am J Med Genet 94:254-261.

Zollino M, Lecce R, Fischetto R, Murdolo M, Faravelli F, Selicorni A, Butte C, Memo L, Capovilla G, Neri G. 2003. Mapping the Wolf-Hirschhorn syndrome phenotype outside the currently accepted WHS critical region and defining a new critical region, WHSCR-2. Am J Hum Genet 72:590-597. 